\title{
INTERESTERIFICAÇÃO QUÍMICA DE ÓLEO DE SOJA E ÓLEO DE SOJA TOTALMENTE HIDROGENADO: INFLUÊNCIA DO TEMPO DE REAÇÃO
}

\author{
Ana Paula Badan Ribeiro*, Monise Helen Masuchi, Renato Grimaldi e Lireny Aparecida Guaraldo Gonçalves \\ Departamento de Tecnologia de Alimentos, Faculdade de Engenharia de Alimentos, Universidade Estadual de Campinas, CP 6091, \\ 13081-970 Campinas - SP, Brasil
}

Recebido em 3/6/08; aceito em 11/11/08; publicado na web em 26/2/09

\begin{abstract}
CHEMICAL INTERESTERIFICATION OF SOYBEAN OIL AND FULLY HYDROGENATED SOYBEAN OIL: INFLUENCE OF THE REACTION TIME. Chemical interesterification is an important alternative to produce zero trans fats. In practice, however, excessive reaction times are used to ensure complete randomization. This work evaluated the influence of the reaction time on the interesterification of soybean oil/fully hydrogenated soybean oil blend, carried out in the following conditions: $100{ }^{\circ} \mathrm{C}, 500 \mathrm{rpm}$ stirring speed, $0.4 \%(\mathrm{w} / \mathrm{w})$ sodium methoxide catalyst. The triacylglycerol composition, solid fat content and melting point analysis showed that the reaction was very fast, reaching the equilibrium within $5 \mathrm{~min}$. This result suggests the interesterification can be performed in substantially lower times, with reduction in process costs.
\end{abstract}

Keywords: chemical interesterification; reaction time; low trans fat.

\section{INTRODUÇÃO}

A maioria dos óleos e gorduras naturais apresenta aplicação limitada em suas formas inalteradas, impostas pela sua composição particular em ácidos graxos e triacilgliceróis (TAG). ${ }^{1}$ Devido à crescente preocupação sobre o impacto nutricional dos ácidos graxos trans na saúde, a interesterificação química tem-se mostrado o principal método para preparação de gorduras plásticas com ausência destes compostos. ${ }^{2}$ Este processo permite a modificação de óleos e gorduras, oferecendo contribuições importantes para o aumento e otimização do uso dos mesmos nos produtos alimentícios. ${ }^{3}$

Em particular, neste processo, óleos e gorduras, isentos de umidade, são aquecidos a $80-100^{\circ} \mathrm{C}$ e o catalisador, geralmente metóxido de sódio, é adicionado em proporções apropriadas (0,1-0,5\%). A reação é conduzida em um intervalo de tempo pré-determinado e finalizada com adição de água ou solução ácida, desativando o catalisador. $\mathrm{Na}$ reação de interesterificação, os grupamentos ésteres, derivados de ácidos graxos, presentes nos triacilgliceróis iniciais não são quimicamente modificados, porém ocorre uma troca desses fragmentos, gerando novos triacilgliceróis com composição geral diferenciada da inicial. As propriedades finais da nova composição triacilglicerólica são totalmente determinadas pela composição total em ácidos graxos das matérias-primas iniciais. A reação é freqüentemente monitorada através de alteração do ponto de fusão e perfil de sólidos. ${ }^{4}$

A reação de interesterificação química consiste de três estágios: ativação do catalisador (indução), clivagem das ligações éster e intercâmbio de ácidos graxos. As diferenças de energia entre as várias combinações de triacilgliceróis são insignificantes e não conduzem, portanto, à seletividade de ácidos graxos. Logo, a reação é randômica e entropicamente dirigida até que o equilíbrio termodinâmico seja alcançado. ${ }^{5,6}$

Embora existam diversos estudos sobre o mecanismo da interesterificação química e produtos interesterificados, a cinética da reação ainda é pouco explorada na literatura. ${ }^{7}$ Neste sentido, apenas a temperatura de reação se revela como parâmetro praticamente consolidado. Konishi et al. ${ }^{8}$ mostraram que a faixa de temperatura ideal

\footnotetext{
*e-mail: badanribeiro@yahoo.com.br
}

para ativação do metóxido de sódio encontra-se entre 100 a $110{ }^{\circ} \mathrm{C}$. Segundo revisão de Dijkstra, ${ }^{9}$ a temperatura de $100{ }^{\circ} \mathrm{C}$ é empregada na maioria dos trabalhos sobre o tema.

Entretanto, verifica-se tipicamente que a interesterificação química tem sido conduzida em intervalos relativamente longos, de 20 a 40 min, com o objetivo de garantir completa randomização. Contudo, com a diminuição desse tempo de reação haveria, conseqüentemente, diminuição de custo do processo e melhor aproveitamento da capacidade dos reatores, além de diminuir a probabilidade de formação de sabões, principal subproduto da reação. ${ }^{5,10,11}$ Ainda, a importância de um estudo minucioso do tempo de reação reside no fato de que a intensidade de formação de novas espécies triacilglicerólicas pode afetar consideravelmente as propriedades físicas das bases oleosas. ${ }^{12}$ Gorduras parcialmente interesterificadas apresentam teor de sólidos, composição triacliglicerólica e comportamento de cristalização que diferem substancialmente da mistura inicial e do produto completamente randomizado. Estes produtos consistem em frações oleosas com propriedades únicas, que podem ser aplicados diretamente como ingredientes plásticos. ${ }^{10,11,13}$

Gioielli e Baruffaldi ${ }^{14}$ estudaram a interesterificação de misturas de óleos de babaçu/dendê, com coleta de frações a cada $5 \mathrm{~min}$, durante $45 \mathrm{~min}$. O equilíbrio da reação foi alcançado entre 20 e 25 min após introdução do catalisador metóxido de sódio. Marangoni e Rousseau ${ }^{10}$ acompanharam a interesterificação de misturas óleo de palma/óleo de soja e banha/óleo de canola, durante 12 e 24 h, respectivamente, com uso de $0,5 \%$ de metóxido de sódio, a $80{ }^{\circ} \mathrm{C}$. A maior variação nas proporções relativas dos triacilgliceróis ocorreu em 30 min para a mistura óleo de palma/óleo de soja e em 1 h para a mistura banha/óleo de canola. A otimização da interesterificação do óleo de palma foi realizada por Grimaldi et al. ${ }^{15} \mathrm{~A}$ variabilidade nos teores de triacilgliceróis em relação ao controle, em conjunto com o menor tempo de reação, foi o fator determinante na escolha da melhor condição, que consistiu em 0,4\% de metóxido de sódio e 20 min de reação. Dijkstra et al., ${ }^{13}$ estudando a interesterificação de misturas 1:1 trilaurina/trioleína, a $90{ }^{\circ} \mathrm{C}$ e com $0,2 \%$ de metóxido de sódio, verificaram que o equilíbrio ocorreu em 10 min de reação.

A interesterificação de misturas de óleos vegetais totalmente hidrogenados com óleos líquidos representa, atualmente, a melhor 
opção para produção de gorduras low trans com diversas finalidades industriais. Face à sua importância econômica e grande disponibilidade, o óleo de soja (OS) apresenta-se como matéria-prima interessante para a elaboração de frações gordurosas isentas de ácidos graxos trans. Para que haja aumento do ponto de fusão destas frações, o uso do óleo de soja totalmente hidrogenado (OSTH), também zero trans, mostra-se altamente favorável. ${ }^{16,17} \mathrm{~A}$ interesterificação de misturas OS/ OSTH tem sido comumente relatada para teores de OSTH de 10 a $50 \%$, com 0,2 a $0,5 \%$ de $\mathrm{MeONa}$ e temperaturas entre 60 a $110{ }^{\circ} \mathrm{C}$, com duração de 15 a 95 min. ${ }^{18-21}$

Este trabalho teve como objetivo realizar o monitoramento da interesterificação química de mistura $60 \% \mathrm{OS} / 40 \% \mathrm{OSTH}$, a fim de verificar as alterações químicas e físicas do processo como função do tempo de reação. Esta fração foi escolhida devido a seu alto ponto de fusão e elevado teor de triacilgliceróis trissaturados, de forma a viabilizar o acompanhamento destas propriedades durante a interesterificação química.

\section{PARTE EXPERIMENTAL}

\section{Material}

\section{Matérias-primas}

Foram utilizados óleo de soja (OS) refinado, adquirido em comércio local, e óleo de soja totalmente hidrogenado (OSTH), gentilmente cedido por indústria do ramo. O catalisador empregado para as reações de interesterificação foi o metóxido de sódio (em pó 99\%, Sigma- Alldrich).

\section{Equipamentos}

As reações foram realizadas em reator de vidro em borossilicato (500 mL), encamisado, com saída de fundo e juntas cônicas esmerilhadas, acoplado a: banho termostatizado com recirculação (LAUDA RE $212,-30 \mathrm{a}+200{ }^{\circ} \mathrm{C}, \pm 0,02^{\circ} \mathrm{C}$ ), sistema de agitação (motor universal com variador eletrônico de velocidade até $4000 \mathrm{rpm}$ - Marconi, $\mathrm{BR}$ ) com haste de agitação para escoamento axial, bomba de vácuo (Vacuubrand modelo 30, bomba tipo diafragma) e termômetro digital tipo espeto $\left(-50 \mathrm{a}+300{ }^{\circ} \mathrm{C}, \pm 1{ }^{\circ} \mathrm{C}\right.$ - Incoterm).

\section{Interesterificação química}

Para a reação utilizou-se $200 \mathrm{~g}$ de mistura $60 \%$ OS/40\%OSTH $(\mathrm{m} / \mathrm{m})$, previamente fundida e homogeneizada durante $10 \mathrm{~min}$ a 100 ${ }^{\circ} \mathrm{C}$ até completa fusão dos cristais. Procedeu-se à secagem da mesma no reator, sob vácuo e agitação de $500 \mathrm{rpm}$, a $100{ }^{\circ} \mathrm{C}$, por $20 \mathrm{~min}$. O teor de catalisador utilizado foi igual a $0,4 \%(\mathrm{~m} / \mathrm{m})$, conforme otimização realizada por Grimaldi et al. ${ }^{15} \mathrm{~A}$ reação foi conduzida sob vácuo, a $100{ }^{\circ} \mathrm{C}$, com agitação de $500 \mathrm{rpm}$, durante $40 \mathrm{~min}$. Foram coletadas amostras ( $20 \mathrm{~g})$ em intervalos regulares de $5 \mathrm{~min}$, garantindo-se ausência de ar no sistema devido ao forte vácuo utilizado. As amostras foram imediatamente agitadas com adição de água destilada e solução de ácido cítrico 5\% para interrupção da reação. As alíquotas foram cuidadosamente lavadas com água destilada (80 ${ }^{\circ} \mathrm{C}$ ) para retirada dos sabões formados e, em seguida, secas a 110 ${ }^{\circ} \mathrm{C}$, por $30 \mathrm{~min}$.

\section{Metodologias analíticas}

\section{Composição em ácidos graxos}

A análise da composição em ácidos graxos foi realizada em cromatógrafo em fase gasosa com coluna capilar - CGC Agilent 6850 Series GC System, após esterificação utilizando o método de Hartman e Lago. ${ }^{22}$ Os ésteres metílicos de ácidos graxos foram se- parados de acordo com o método $\mathrm{AOCS}^{23} \mathrm{Ce} 2-66$ em coluna capilar DB-23 Agilent (50\% cyanopropyl-methylpolysiloxano), dimensões $60 \mathrm{~m}, \phi$ int: $0,25 \mathrm{~mm}, 0,25 \mu \mathrm{m}$ filme. Temperatura do forno de 110 ${ }^{\circ} \mathrm{C}-5 \mathrm{~min}, 110-215{ }^{\circ} \mathrm{C}\left(5^{\circ} \mathrm{C} / \mathrm{min}\right), 215^{\circ} \mathrm{C}-24 \mathrm{~min}$; temperatura do detector $280^{\circ} \mathrm{C}$; temperatura do injetor $250{ }^{\circ} \mathrm{C}$; gás de arraste hélio; razão split 1:50; volume injetado $1,0 \mu \mathrm{L}$. A composição qualitativa foi determinada por comparação dos tempos de retenção dos picos com os dos respectivos padrões de ácidos graxos.

\section{Composição triacilglicerólica}

A análise da composição em triacilgliceróis foi realizada em cromatógrafo gasoso capilar CGC Agilent 6850 Series GC System. Foi utilizada coluna capilar DB-17HT Agilent Catalog: 122-1811 (50\% phenyl-methylpolysiloxane, com $15 \mathrm{~m}$ de comprimento $\mathrm{x} 0,25$ mm de diâmetro interno e contendo $0,15 \mu \mathrm{m}$ de filme) As condições foram: injeção split, razão de 1:100; temperatura da coluna $250{ }^{\circ} \mathrm{C}$, programada até $350{ }^{\circ} \mathrm{C}$ à razão de $5{ }^{\circ} \mathrm{C}$ por minuto; gás de arraste hélio, vazão de $1,0 \mathrm{~mL}$ por minuto; temperatura do injetor $360{ }^{\circ} \mathrm{C}$; temperatura do detector $375^{\circ} \mathrm{C}$; volume injetado $1,0 \mu \mathrm{L}$; concentração da amostra: $100 \mathrm{mg} / 5 \mathrm{~mL}$ de tetra-hidrofurano. A identificação dos grupos de triacilgliceróis foi realizada através da comparação dos tempos de retenção, segundo os procedimentos de Grimaldi ${ }^{24} \mathrm{e}$ Antoniossi Filho. ${ }^{25,26} \mathrm{~A}$ composição em triacilgliceróis das matérias-primas foi também obtida teoricamente através do software 1,2,3 Óleos, baseada na hipótese de distribuição 1,3-random-2-random, que prevê a porcentagem molar dos triacilgliceróis presentes em óleos vegetais, a partir da composição em ácido graxos destas amostras.

\section{Conteúdo de gordura sólida}

Foi determinado utilizando espectrômetro de ressonância magnética nuclear (RMN) Bruker pc120 Minispec e banhos secos de alta precisão $\left(0-70{ }^{\circ} \mathrm{C}\right) \mathrm{TCON} 2000$ (Duratech, EUA). Método $\mathrm{AOCS}^{23} \mathrm{Cd}$ 16b-93: método direto, leitura das amostras em série nas temperaturas de $10 ; 20 ; 25 ; 30 ; 35 ; 40 ; 45 ; 50 ; 55$ e $60{ }^{\circ} \mathrm{C}$, com temperagem para gorduras não estabilizadas.

\section{Ponto de fusão}

Determinado utilizando tubo capilar aberto, segundo as normas da AOCS, ${ }^{23}$ método Cc 3-25. Adicionalmente, o ponto de fusão foi calculado para a temperatura correspondente ao teor de sólidos igual a $4 \%$ obtido por RMN, segundo metodologia de Karabulut et al., ${ }^{27}$ através de equações polinomiais ajustadas com auxílio do Software Statistica 6.0. ${ }^{28}$ Foi aplicado um modelo de regressão linear simples relacionando os resultados obtidos pelos dois métodos.

\section{Índice de iodo e índice de saponificação}

Calculados a partir da composição em ácidos graxos segundo os métodos $\mathrm{AOCS}^{23} \mathrm{Cd} 1 \mathrm{c}-85$ e Cd 31-94, respectivamente.

Ácidos graxos livres

Determinados pelo método $\mathrm{AOCS}^{23} \mathrm{Ca} 5 \mathrm{a}-40$.

Índice de peróxido

Determinado pelo método $\mathrm{AOCS}^{23} \mathrm{Cd} 8 \mathrm{~b}-90$.

Sabões

Determinados pelo método $\mathrm{AOCS}^{23} \mathrm{Cc} 17-79$.

\section{RESULTADOS E DISCUSSÃO}

A qualidade do óleo utilizado na reação de interesterificação química é fundamental. "Venenos" catalíticos, como ácidos graxos livres, peróxidos, umidade e sabões podem provocar queda na ativida- 
de do $\mathrm{MeONa} .{ }^{29}$ As características de qualidade das matérias-primas utilizadas constam da Tabela 1 e atendem os parâmetros de qualidade descritos por Erickson. ${ }^{30}$ A Tabela 2 apresenta a composição em ácidos graxos e os valores de índice de iodo e saponificação do OS, OSTH e da mistura $60 \%$ OS/40\%OSTH. Estes resultados exprimem a média de duas determinações e estão de acordo com os limites encontrados na literatura. ${ }^{16,30}$

Tabela 1. Características de qualidade das matérias-primas

\begin{tabular}{lcc}
\hline Determinações & OS & OSTH \\
\hline AGL $(\%)$ & 0,03 & 0,04 \\
Índice de peróxido (meq O $/ \mathrm{kg}$ amostra) & 1,04 & 0 \\
Sabões $(\mathrm{mg} / \mathrm{kg})$ & 0 & 0 \\
\hline
\end{tabular}

Tabela 2. Composição em ácidos graxos (\%) e índices de iodo e saponificação das matérias-primas e mistura 60\%OS/40\%OSTH

\begin{tabular}{lccc}
\hline Ácidos graxos $(\%)$ & OS & $60 \%$ OS/40\%OSTH & OSTH \\
\hline C14:0 mirístico & 0,08 & 0,10 & 0,12 \\
C16:0 palmítico & 11,37 & 11,31 & 11,50 \\
C16:1 palmitoléico & 0,08 & - & - \\
C18:0 esteárico & 3,46 & 37,54 & 86,62 \\
C18:1 oléico & 23,17 & 13,77 & 0,11 \\
C18:2 linoléico & 54,87 & 32,69 & 0,18 \\
C18:3 linolênico & 5,32 & 3,16 & - \\
C20:0 araquídico & 0,38 & 0,54 & 0,74 \\
C20:1 gadoléico & 0,24 & 0,14 & - \\
C22:0 behênico & 0,51 & 0,54 & 0,53 \\
C24:0 lignocérico & 0,18 & 0,20 & 0,19 \\
$\sum$ Saturados & 15,98 & 50,23 & 99,71 \\
$\sum$ Insaturados & 84,02 & 49,77 & 0,29 \\
I.V* & 135 & 80 & 0,4 \\
I.S* & 193 & 192 & 189 \\
\hline
\end{tabular}

$\mathrm{I} . \mathrm{V}^{*}=$ Índice de iodo $(\mathrm{g} \mathrm{I} / 100 \mathrm{~g}) ; \mathrm{I} . \mathrm{S}^{*}=$ Índice de saponificação (mg KOH/g)

Óleos e gorduras são considerados amostras complexas, devido ao grande número de diferentes triacilgliceróis que os compõem. Desta maneira, a identificação de triacilgliceróis torna-se um difícil processo, no qual o número de possíveis formas estruturais é muito grande comparado ao número de ácidos graxos presentes. ${ }^{31} \mathrm{~A}$ Tabela 3 mostra os principais triacilgliceróis individuais que compõem os diversos grupos classificados segundo o número de carbonos, para as matérias-primas, conforme análise experimental e resultados teóricos.

Comparando-se os resultados experimental e teórico, verificase que os mesmos apresentam boa concordância. Para o OS, os triacilgliceróis em maiores quantidades obtidos teoricamente foram os mesmos obtidos através do método cromatográfico: PLL, OLO, OLL e LLL. As espécies PLS, OOO e SLL não foram detectadas pelo método teórico. A Tabela 4 apresenta a composição das matériasprimas segundo teores de triacilgliceróis dos tipos trissaturados (SSS), monoinsaturados (SSU), diinsaturados (SUU) e triinsaturados (UUU), conforme as duas metodologias empregadas. O teor total de triinsaturados do OS correspondeu a 59,12 e a 63,33\% segundo os métodos experimental e teórico, respectivamente. O OSTH apre-
Tabela 3. Composição em triacilgliceróis individuais e quanto ao número de carbono (NC) do óleo de soja (OS) e óleo de soja totalmente hidrogenado $(\mathrm{OSTH})$, obtida teoricamente $\left(\mathrm{T}^{*}\right)$ e por cromatografia em fase gasosa

\begin{tabular}{|c|c|c|c|c|c|}
\hline $\mathrm{NC}$ & TAG $(\%)$ & OS & OS (T*) & OSTH & OSTH $\left(\mathrm{T}^{*}\right)$ \\
\hline \multirow[t]{3}{*}{ C50 } & PPS & - & - & 4,17 & 3,82 \\
\hline & POP & 0,81 & 0,95 & - & - \\
\hline & PLP & 3,02 & 2,27 & - & - \\
\hline \multirow[t]{7}{*}{ C52 } & PSS & - & - & 30,79 & 26,70 \\
\hline & POS & 0,22 & 0,59 & - & - \\
\hline & POO & 3,55 & 3,29 & - & - \\
\hline & PLS & 0,67 & - & - & - \\
\hline & PLO & 10,38 & 9,27 & - & - \\
\hline & PLL & 15,62 & 12,32 & - & - \\
\hline & PLnL & 2,82 & 2,18 & - & - \\
\hline \multirow[t]{9}{*}{ C54 } & SSS & - & - & 63,35 & 67,43 \\
\hline & SOO & 0,76 & 0,99 & - & - \\
\hline & OOO & 3,79 & - & - & - \\
\hline & SLO & 1,68 & 4,22 & - & - \\
\hline & OLO & 10,25 & 12,86 & - & - \\
\hline & SLL & 1,09 & - & - & - \\
\hline & OLL & 18,99 & 23,54 & - & - \\
\hline & LLL & 21,06 & 21,67 & - & - \\
\hline & LLnL & 5,02 & 5,26 & - & - \\
\hline \multirow[t]{3}{*}{ C56 } & SSA & - & - & 1,69 & 2,05 \\
\hline & ALL & 0,25 & 0,59 & - & - \\
\hline & SLA & - & - & - & - \\
\hline
\end{tabular}

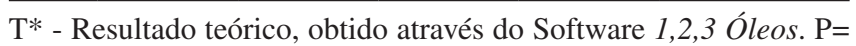
ácido palmítico; $\mathrm{S}=$ ácido esteárico; $\mathrm{O}=$ ácido oléico; $\mathrm{L}=$ ácido linoléico; $\mathrm{Ln}=$ ácido linolênico; $\mathrm{A}=$ ácido araquídico. -: não detectado

sentou totalidade de triacilgliceróis do tipo SSS. No que se refere à distribuição experimental quanto ao número de carbono, o OS e o OSTH perfazem, respectivamente: C50 - 3,83 e 4,17\%; C52 - 33,27 e $30,79 \%$; C54-62,65 e 63,35\%; C56-0,25 e 1,69\%.

As análises da composição triacilglicerólica representam uma indicação verdadeira de como ocorre o processo de randomização, sendo extremamente úteis para monitorar a modificação de gorduras interesterificadas e delinear aplicações específicas para as mesmas. ${ }^{16}$ Na Tabela 5 são mostrados os resultados de composição triacilglicerólica da mistura $60 \% \mathrm{OS} / 40 \% \mathrm{OSTH}$ segundo o tempo de reação.

Tabela 4. Teores de SSS, SSU, SUU e UUU do óleo de soja (OS) e óleo de soja totalmente hidrogenado (OSTH), obtidos teoricamente $\left(\mathrm{T}^{*}\right)$ e por cromatografia em fase gasosa

\begin{tabular}{lcccc}
\hline TAG $(\%)$ & OS & OS $\left(\mathrm{T}^{*}\right)$ & OSTH & OSTH $\left(\mathrm{T}^{*}\right)$ \\
\hline SSS & - & - & 100,00 & 100,00 \\
SSU & 4,72 & 3,81 & - & - \\
SUU & 36,16 & 32,86 & - & - \\
UUU & 59,12 & 63,33 & - & - \\
\hline
\end{tabular}

T* - Resultado teórico, obtido através do Software 1,2,3 Óleos. -: não detectado 
Verifica-se igual número de triacilgliceróis distintos antes e durante a reação de interesterificação. Entretanto, três novas espécies triacilglicerólicas foram formadas: POS, SOS e SLS, esta última em proporções relativamente altas em relação à composição total, enquanto os triacilgliceróis POO, PLnL e OOO, que se apresentavam em pequenas quantidades na mistura de partida, desapareceram com a reação. Ainda, os teores de PLS, SLO e SLL aumentaram expressivamente com a interesterificação. Ocorreu variação de todos os tipos de triacilgliceróis com a reação, comprovando-se o rearranjo dos ácidos graxos, conforme a Figura 1.

Os triacligliceróis predominantes na mistura interesterificada, independentemente do tempo de reação, consistiram do SLS e SLL, com teores médios em torno de $12 \%$. Os demais ácidos graxos presentes na mistura avaliada e que não constituem as espécies triacilglicerólicas verificadas na Tabela 5, provavelmente contribuíram para a formação de triacilgliceróis em quantidades mínimas, de difícil separação ou detecção.

É possível observar que a maior variação nos teores de triacilgliceróis ocorreu entre os tempos 0 e $5 \mathrm{~min}$, ou seja, praticamente no início da reação. A partir dos 5 min de reação, as alterações relativas nas porcentagens de cada espécie triacilglicerólica mostram-se pouco significativas em função do tempo de reação. Este fato pode ser facilmente verificado mediante a queda expressiva no teor de SSS durante os $5 \mathrm{~min}$ iniciais de reação, em que esta porcentagem passa de 28,75 a 10,18\%, o que representa uma variação de $64 \%$. Adicionalmente, observa-se que a formação dos triacilgliceróis SOS e SLS e os expressivos acréscimos de 89 e $94 \%$, respectivamente, nos teores de SLO e SLL, ocorreram nos 5 min iniciais da interesterificação. A partir de 5 min de reação, os resultados sugerem pequenas oscilações segundo o tempo de reação, que podem estar associadas a uma reação em estado de equilíbrio, conforme estudos de Konishi et al.. ${ }^{8}$ A Figura 2 mostra o acompanhamento da reação de interesterificação em função dos teores de triacilgliceróis trissaturados, monoinsaturados, di- e triinsaturados.

A interesterificação resultou na diminuição simultânea dos triacilgliceróis de maior e menor pontos de fusão, com formação expressiva de espécies intermediárias (SSU e SUU). Segundo O'Brien, ${ }^{16}$ as propriedades de alimentos gordurosos podem ser relacionadas à composição triacilglicerólica da gordura que os compõe. Os triacilgliceróis SSU, com pontos de fusão entre 27 a $42{ }^{\circ} \mathrm{C}$, são responsáveis pela estrutura destes produtos. Os triacilgliceróis SUU são importantes no que se refere às propriedades de fusão à temperatura corporal e plasticidade dos mesmos à temperatura ambiente. Logo, o acréscimo nos teores de SSU e SUU promovido pela interesterificação química está associado ao aumento da funcionalidade tecnológica, à melhoria das características sensoriais e, portanto, ao maior potencial de aplicação desta gordura interesterificada em alimentos.

Verificou-se que nos 5 min iniciais da reação os teores de SSS e UUU diminuíram consideravelmente (55,5 e 51,7\%, respectivamente), enquanto ocorreu o rápido acréscimo nos teores de triacillgliceróis dos tipos SSU e SUU, nas proporções de 92,9 e 38,7\%. Aos 15 min de reação, os teores de SSS e SSU alcançaram o teor mínimo (13,9\%) e máximo $(36,1 \%)$, respectivamente. Porém, aos 30 min de reação a porcentagem de SSS foi igual a 20,8\%, similar ao teor verificado aos 5 min de reação $(19,6 \%)$, o mesmo ocorrendo para o teor de SSU. Assim, é possível observar que a partir dos 5 min iniciais, os teores de SSS, SSU, SUU e UUU oscilaram conjuntamente, com variações

Tabela 5. Composição triacilglicerólica da mistura 60\%OS/40\%OSTH segundo o tempo de reação de interesterificação química, obtida através de cromatografia em fase gasosa

\begin{tabular}{|c|c|c|c|c|c|c|c|c|c|}
\hline \multirow[b]{2}{*}{ TAG $(\%)$} & \multicolumn{9}{|c|}{ Tempo de reação (min) } \\
\hline & 0 & 5 & 10 & 15 & 20 & 25 & 30 & 35 & 40 \\
\hline PPS & 1,86 & 1,94 & 1,71 & 1,89 & 1,92 & 1,39 & 1,97 & 2,32 & 1,86 \\
\hline POP & 0,46 & 0,72 & 0,54 & 0,73 & 0,77 & 0,44 & 1,00 & 1,21 & 0,75 \\
\hline PLP & 1,48 & 1,66 & 1,84 & 1,79 & 1,82 & 1,67 & 2,02 & 2,48 & 1,84 \\
\hline PSS & 13,07 & 7,49 & 7,36 & 5,87 & 7,41 & 6,36 & 7,29 & 7,96 & 7,12 \\
\hline POS & - & 3,46 & 2,77 & 4,87 & 2,73 & 2,57 & 2,84 & 3,16 & 3,33 \\
\hline POO & 1,92 & - & - & - & - & - & - & - & - \\
\hline PLS & $\mathbf{0 , 3 7}$ & 8,14 & 8,12 & 8,37 & $\mathbf{9 , 5 4}$ & 8,33 & 7,89 & 8,80 & 8,61 \\
\hline PLO & 5,80 & 4,89 & 4,28 & 3,60 & 4,21 & 4,78 & 4,36 & 4,52 & 4,31 \\
\hline PLL & 8,07 & 6,57 & 5,98 & 5,88 & 6,62 & 7,17 & 5,89 & 6,14 & 6,02 \\
\hline PLnL & 1,85 & - & - & - & - & - & - & - & - \\
\hline SSS & 28,75 & 10,18 & 7,70 & 6,20 & 8,10 & 10,02 & 11,55 & 10,98 & 10,43 \\
\hline SOS & - & 6,50 & 8,35 & 6,71 & 6,03 & 4,25 & 4,92 & 5,25 & 4,86 \\
\hline SLS & - & 11,90 & 11,76 & 13,61 & 12,97 & 11,49 & 11,58 & 11,85 & 11,73 \\
\hline $\mathrm{OOO}$ & 2,21 & - & - & - & - & - & - & - & - \\
\hline SLO & 0,99 & 8,88 & 8,78 & 9,97 & 9,48 & 8,67 & 8,74 & 8,55 & $\mathbf{9 , 4 3}$ \\
\hline OLO & 5,77 & 1,10 & 1,22 & 1,30 & 1,11 & 1,28 & 1,26 & 1,07 & 1,23 \\
\hline SLL & 0,64 & 11,10 & 12,34 & 13,18 & 11,28 & 12,95 & 12,71 & 10,83 & 12,45 \\
\hline OLL & 11,22 & 6,90 & 6,89 & 6,73 & 6,01 & 7,41 & 5,47 & 5,93 & 6,06 \\
\hline LLL & 11,88 & 7,60 & 8,31 & 7,84 & 8,42 & 9,28 & 8,64 & 7,65 & 8,18 \\
\hline LLnL & 3,26 & 0,98 & 2,04 & 1,46 & 1,55 & 1,97 & 1,85 & 1,26 & 1,78 \\
\hline
\end{tabular}

$\mathrm{P}=$ ácido palmítico; $\mathrm{S}=$ ácido esteárico; $\mathrm{O}=$ ácido oléico; $\mathrm{L}=$ ácido linoléico; $\mathrm{Ln}$ = ácido linolênico. -: não detectado 
(a)
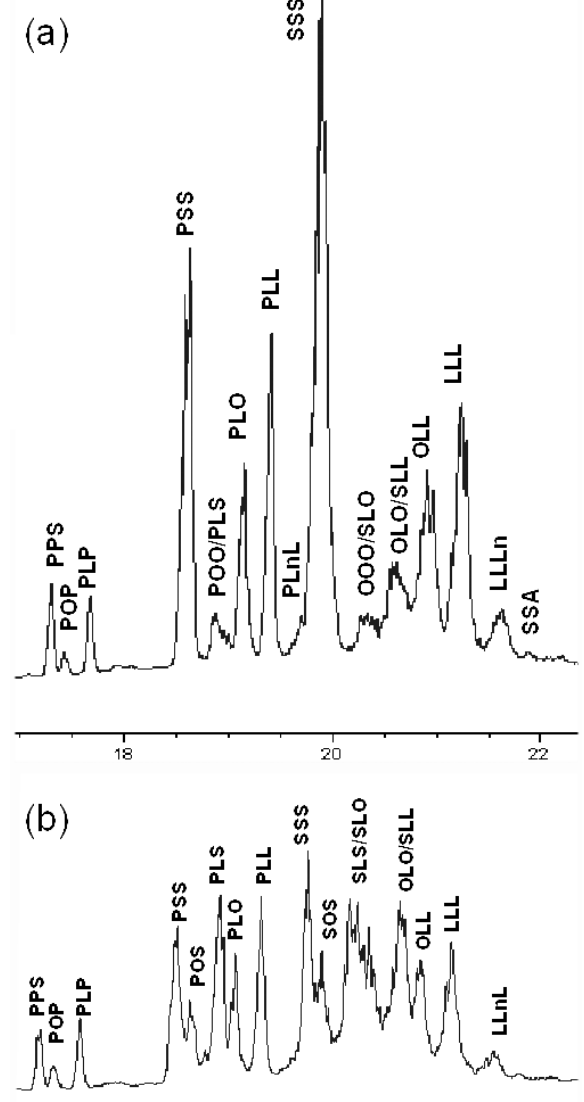

18 a etanólise de óleo de mamona, realizada a $80{ }^{\circ} \mathrm{C}$ com catalisador metóxido de sódio (etanol/óleo/catalisador em razão molar de 6:10:2) e monitorada durante $10 \mathrm{~h}$, apresentou máxima taxa de conversão em ésteres etílicos em $6 \mathrm{~h}$ de reação. Após este período, verificou-se reversibilidade da reação.

A análise da Figura 2 permite a observação deste fenômeno. Contudo, embora ocorra reversão do rearranjo das espécies triacliglicerólicas, este acontece apenas após um estado de relativo equilíbrio alcançado nos minutos iniciais de reação. Comportamento similar foi reportado por Musavi et al., ${ }^{7}$ a partir do estudo da cinética de interesterificação do óleo de soja. A proporção inicial de ácido palmítico na posição $s n$-2 dos triacilgliceróis era igual a 1,28\% e aumentou para $12,5 \%$ quando a reação alcançou o equilíbrio, em menos de $5 \mathrm{~min}$ de reação, a $80{ }^{\circ} \mathrm{C}, 0,4 \%$ de $\mathrm{MeONa}$ e agitação de $600 \mathrm{rpm}$. O teor de ácido palmítico na posição $s n-2$ atingiu $4 \%$ imediatamente após adição do catalisador, indicando uma reação extremamente rápida.

A alteração da composição triacilglicerólica refletiu-se em modificação do conteúdo de gordura sólida da mistura interesterificada. A partir de metodologia descrita por Coenen ${ }^{34} \mathrm{e}$ adaptada por Rousseau e Marangoni ${ }^{6}$ foi construído o gráfico do conteúdo de gordura sólida em função do tempo de reação, para cada temperatura de leitura, que consta da Figura 3.

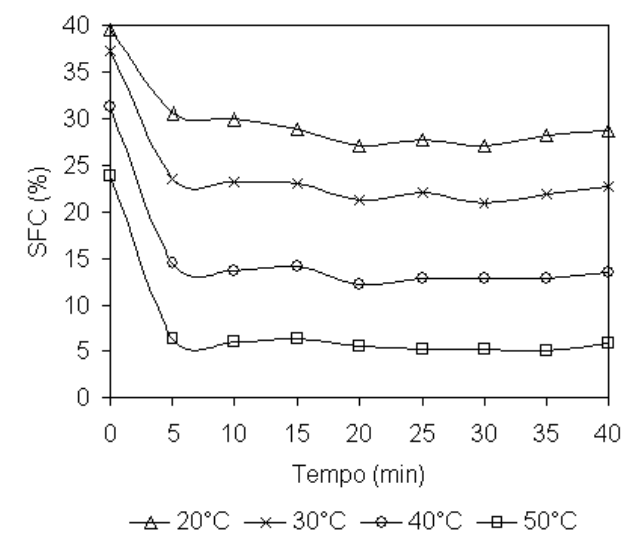

Figura 3. Conteúdo de gordura sólida a 10, 20, 30 e $40^{\circ} \mathrm{C}$, da mistura $60 \%$ OS/40\% OSTH, em função do tempo de reação de interesterificação química

A $30^{\circ} \mathrm{C}$, a porcentagem de gordura sólida da amostra inicial correspondeu a $37,2 \%$. Considerando a média de todas as amostras, após a interesterificação o conteúdo de gordura sólida a esta temperatura foi igual a 22,4\%. Estes resultados são coerentes com os obtidos por Petrauskaite et al..${ }^{20}$ para mistura $60 \% \mathrm{OS} / 40 \% \mathrm{OSTH}$ interesterificada, em que o teor de sólidos a $30^{\circ} \mathrm{C}$ consistiu de $20,3 \%$.

A análise da Figura 3 permite observar que o conteúdo de gordura sólida apresentou decréscimo significativo nos minutos iniciais de reação, mantendo-se praticamente inalterado após $5 \mathrm{~min}$ de processo. De acordo com Coenen, ${ }^{34}$ este comportamento sugere que a reação é bastante rápida e que, uma vez que haja concentração suficiente de catalisador, a reação requer somente alguns minutos, a menos que sejam utilizadas baixas temperaturas.

As oscilaç̃os nos teores dos diversos grupos de triacilgliceróis, a partir dos 5 min de reação, verificadas na Figura 2, não se refletiram em oscilações no conteúdo de gordura sólida com o tempo de interesterificação. Este fato pode estar relacionado a uma dinâmica de compensação que não afeta a curva de sólidos.

A Figura 4 mostra os valores dos pontos de fusão (obtidos através do método matemático descrito por Karabulut $e t$ al. $\left.{ }^{27}\right)$ e o teor de triacligliceróis trissaturados em função do tempo de reação. micamente mais favorável. Observação semelhante foi verificada por Meneghetti et al.$^{33}$ em reações de transesterificação. Em particular, percentuais negativas e positivas ao longo do tempo de interesterificação. Estas observações corroboram com os estudos realizados por Grimaldi et al. ${ }^{15} \mathrm{e}$ Wada.$^{32}$ Estes autores ressaltam que o processo de rearranjo dos ácidos graxos ocorre durante um determinado período, mas longos tempos de reação podem conduzir ao rearranjo termodina- 
É possível observar que o declínio do ponto de fusão é expressivo nos primeiros 5 min de reação e oscila conforme as variações nos teores de SSS. A mistura inicial apresentava ponto de fusão igual a $63{ }^{\circ} \mathrm{C}$. Após a reação, as temperaturas de fusão variaram entre 50,9 e $53,7^{\circ} \mathrm{C}$. O menor valor ocorreu a $15 \mathrm{~min}$ de reação, podendo ser explicado pelo concomitante decréscimo nas proporções de triacilgliceróis do tipo SSS, em concordância com os resultados de composição triacilglicerólica obtidos. Ainda, ocorre um acréscimo do ponto de fusão a 30 min de reação $\left(53{ }^{\circ} \mathrm{C}\right)$, associado provavelmente ao aumento de $34,3 \%$ no teor de SSS em relação ao verificado a 15 min de interesterificação. Portanto, o acompanhamento do ponto de fusão da mistura interesterificada também evidenciou certo grau de reversão da interesterificação química, embora a níveis delimitados após expressiva modificação da matéria-prima.

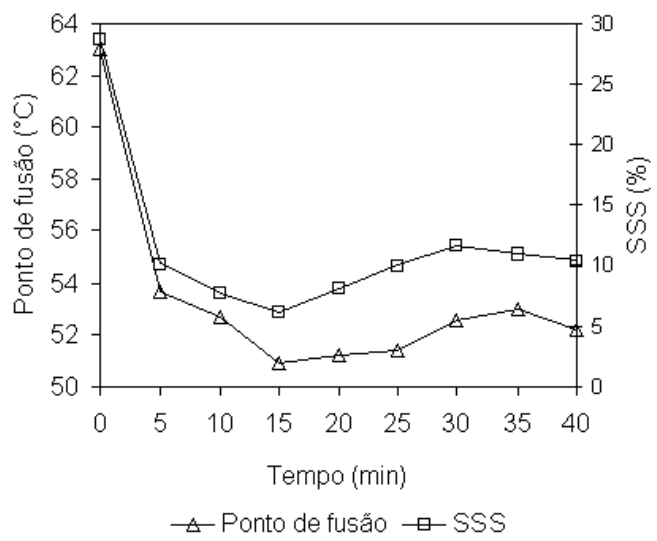

Figura 4. Ponto de fusão e teor de triacilgliceróis trissaturados em função do tempo de reação de interesterificação química de mistura $60 \%$ OS/40\%OSTH

Em resumo, uma análise conjunta de todos os resultados permitiu verificar que a reação de interesterificação química apresentou um período inicial associado à intensa randomização, no qual as modificações de composição triacilglicerólica, conteúdo de gordura sólida e ponto de fusão foram representativas da mistura interesterificada. Após este período, a reação foi caracterizada por um estado de relativo equilíbrio, no qual, devido ao tempo relativamente longo de reação, na presença de catalisador, ocorreu pequena reversão da randomização previamente estabelecida aos 5 min de reação. Poder-se-ia assumir, portanto, que é possível a utilização de tempos de reação significativamente menores, escolhidos em função de se objetivar interesterificação parcial ou total.

Um modelo de regressão linear simples foi aplicado relacionando os pontos de fusão obtidos por RMN com os pontos de fusão obtidos pelo método do tubo capilar aberto (Figura 5), para mistura inicial e frações, cuja equação é descrita a seguir:

P.F. $\left({ }^{\circ} \mathrm{C}\right)$ capilar $=0,8725^{*}\left[\right.$ P.F. $\left.\left({ }^{\circ} \mathrm{C}\right) \mathrm{RMN}\right]+4,12$; com coeficiente de correlação $(r)=0,905$.

Houve boa correlação entre os métodos. Este fato corrobora a utilização da técnica de RMN como meio seguro para obtenção do ponto de fusão de gorduras, uma vez que o mesmo se diferencia como uma prática fácil e rápida, podendo ser utilizado para medidas praticamente instantâneas.

\section{CONCLUSÃO}

A interesterificação química consiste em alternativa fundamental para o desenvolvimento de bases gordurosas com ausência de ácidos graxos trans. Apesar dos vários estudos já realizados, tempos relati-

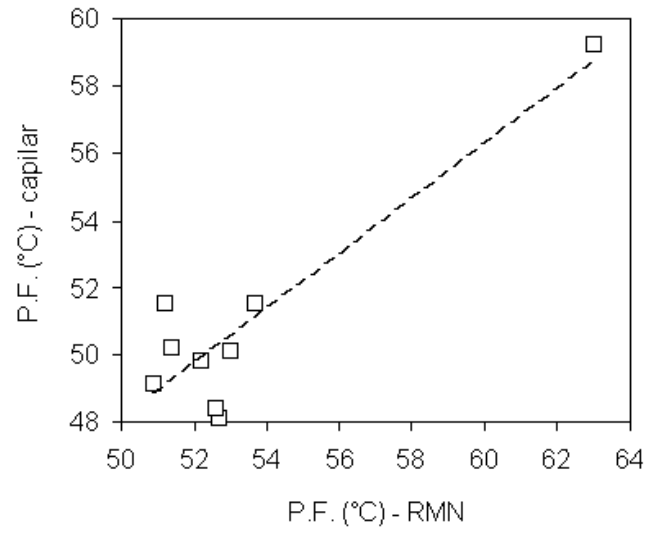

Figura 5. Correlação entre os métodos de ressonância magnética nuclear e tubo capilar aberto para obtenção de pontos de fusão

vamente longos de reação ainda são empregados. Neste trabalho, a interesterificação total de mistura 40\%OS/60\%OSTH foi alcançada aos 5 min de reação, sob condições de $100{ }^{\circ} \mathrm{C}, 0,4 \%$ de catalisador metóxido de sódio e 500 rpm de agitação. Este resultado, verificado a partir de técnicas distintas, como a cromatografia em fase gasosa e a ressonância magnética nuclear, indica que é possível a obtenção de gorduras total ou parcialmente interesterificadas em tempos substancialmente menores, com redução dos custos associados ao processo.

\section{AGRADECIMENTOS}

À Fundação de Amparo à Pesquisa do Estado de São Paulo Fapesp e ao Conselho Nacional de Desenvolvimento Científico e Tecnológico - CNPq, pelo auxílio financeiro e pela concessão da bolsa de doutorado.

\section{REFERÊNCIAS}

1. Chiu, M. C.; Gioielli, L. A.; Grimaldi, R.; Quim. Nova 2008, 31, 238.

2. Norizzah, A. R.; Chong, C. L.; Cheow, C. S.; Zaliha, O.; Food Chem. 2004, 86, 229.

3. Ribeiro, A. P. B.; Moura, J. M. L. N.; Grimaldi, R.; Gonçalves, L. A. G.; Quim. Nova 2007, 30, 1295.

4. Rozendaal, A.; Inform. 1992, 3, 1232.

5. Liu, L.; J. Am. Oil Chem. Soc. 2004, 81, 331.

6. Rousseau, D.; Marangoni, A. G. Em Food Lipids: Chemistry, Nutrition, and Biotechnology; Akoh, C. C.; Min, D. B., eds.; CRC Press: Boca Raton, 2008, cap. 10.

7. Musavi, A.; Tekin, A.; Kaya,M.; Sanal, I.; J. Food Lipids 2003, 10, 277.

8. Konishi, H.; Neff, W. E.; Mounts, T. L.; J. Am. Oil Chem. Soc. 1993, 70, 411.

9. Dijkstra, A. J. Em The Lipid Handbook; Gunstone, F. D., ed.; CRC Press: Boca Raton, 2007, cap. 4.

10. Marangoni, A. G.; Rousseau, D.; J. Am. Oil Chem. Soc. 1998, 75, 1265.

11. Liu, L.; Lampert, D.; J. Am. Oil Chem. Soc. 1999, 76, 783.

12. Ramamurthi, S.; McCurdy, A. R. Em Development and Processing of Vegetable Oils for Human Nutrition; Przybylski, R.; McDonald, B. E., eds.; AOCS Press: Champaign, 2005, cap. 6.

13. Dijkstra, A. J.; Toke, E. R.; Kolonits, P.; Recseg, K.; Kovári, K.; Poppe, L.; Eur. J. Lipid Sci. Technol. 2005, 107, 912.

14. Gioielli, L. A.; Baruffaldi, R.; Rev. Farm. Bioquím. Univ. S. Paulo. 1988, 24, 29. 
15. Grimaldi, R.; Gonçalves, L. A. G.; Ando, M. Y.; Quim. Nova 2005, 28, 633.

16. O'Brien, R. D.; Fats and Oils - Formulating and Processing for Applications, $2^{\text {nd }}$ ed., CRC Press: New York, 2004.

17. Marangoni, A. G.; Rousseau, D.; Trends Food Sci. Technol. 1995, 6, 329.

18. Zeitoun, M. A. M.; Neff, W. E.; List, G. R.; Mounts, T. L.; J. Am. Oil Chem. Soc. 1993, 70, 467

19. List, G. R.; Mounts, T. L.; Orthoefer, F.; Neff, W. E.; J. Am. Oil Chem. Soc. 1995, 72, 379.

20. Petrauskaite, V.; De Greyt, W.; Kellens, M.; Huyghebaert, A.; J. Am. Oil Chem. Soc. 1998, 75, 489.

21. Zomorrodi, S.; Shokrani, R.; Shahedi, M.; Dokhani, S.; Iranian J. Agric. Sci. 2003, 34, 587

22. Hartman, L.; Lago, R. C. A.; Lab. Pract. 1973, 22, 475.

23. AOCS; Official methods and recommended practices of the American Oil Chemists'Society, AOCS Press: Champaign, 2004.

24. Grimaldi, R.; Tese de Doutorado, Universidade Estadual de Campinas, Brasil, 1999.
25. Antoniossi Filho, N. R.; Tese de Doutorado, Universidade de São Paulo, Brasil, 1995.

26. Antoniossi Filho, N. R.; Mendes, O. L.; Lanças, F. M.; Chromatographia 1995, 40, 557.

27. Karabulut, I.; Turan, S.; Ergin, G.; Eur. Food Res. Technol. 2004, 218, 224.

28. Statsoft Inc.; Statistica v.6.0. for windows Vol. IV, Tulsa, Estados Unidos, 2002.

29. Sreenivasan, B.; J. Am. Oil Chem. Soc. 1978, 55, 796.

30. Erickson, D. R.; Practical Handbook of Soybean Processing and Utilization, AOCS Press: Champaign, 1995.

31. http://biodiesel.gov.br, acessada em Fevereiro 2008.

32. Wada, J. K. A.; Dissertação de Mestrado, Universidade Estadual de Campinas, Brasil, 2007.

33. Meneghetti, S. M. P.; Meneghetti, M. R.; Wolf, C. R.; Silva, E. C.; Gilvan, E. S. L.; Coimbra, M. A.; Soletti, J. I.; Carvalho, S. H. V.; J. Am. Oil Chem. Soc. 2006, 83, 819.

34. Coenen, J. W. E.; Rev.Fr. Corps Gras. 1974, 21, 403. 